\title{
In situ formation of gold nanoparticles in polymer inclusion membrane: Application as platform in a label-free potentiometric immunosensor for Salmonella typhimurium detection
}

\author{
Nádia F.D. Silva ${ }^{\mathrm{a}, \mathrm{c}}$, Júlia M.C.S. Magalhães ${ }^{\mathrm{b}, *}$, M. Fátima Barroso ${ }^{\mathrm{a}}$, Teresa Oliva-Teles ${ }^{\mathrm{a}}$, \\ Cristina Freire ${ }^{c}$, Cristina Delerue-Matos ${ }^{\mathrm{a}}$ \\ ${ }^{\text {a }}$ REQUIMTE/LAQV, Instituto Superior de Engenharia do Porto, Instituto Politécnico do Porto, 4200-072 Porto, Portugal \\ ${ }^{\mathrm{b}}$ REQUIMTE/LAQV, Departamento de Engenharia Química, Faculdade de Engenharia, Universidade do Porto, $4200-465$ Porto, Portugal \\ ${ }^{\mathrm{c}}$ REQUIMTE/LAQV, Departamento de Química e Bioquímica, Faculdade de Ciências, Universidade do Porto, $4169-007$ Porto, Portugal
}

A B S T R A C T

\begin{abstract}
Polymeric ion selective electrodes are highly sensitive to changes in zero current ion flow and this offers a route to signal amplification in label-free potentiometric immunosensors. In this work, a label-free potentiometric immunosensor toward Salmonella typhimurium (ST) assembled in a home-made pipette-tip electrode is described. The signal-output amplification was implemented on a gold nanoparticle polymer inclusion membrane (AuNPs-PIM) which was used as sensing platform and for antibody immobilization. Additionally, a marker ion was used to detect the antibody-antigen binding event at the electrode surface. The immunosensor construction was performed in several steps: i) gold salt ions extraction in PVC membrane; ii) AuNPs formation using $\mathrm{Na}_{2}$ EDTA as reduction agent; iii) antibody anti-Salmonella conjugation on AuNPs-PIM in pipette-tip electrodes. The potential shift observed in potentiometric measurements was derived simply from the blocking effect in the ionic flux caused by antigen-antibody conjugation, without no extra steps, mimetizing the ion-channel sensors. A detection limit of 6 cells $\mathrm{mL}^{-1}$ was attained. As proof-of-concept, recovery studies were performed in spiked commercial apple juice samples with success. Due to the simplicity of use, the appealing cost of equipment and sensor production and being able to provide a quick analytical response (less than $1 \mathrm{~h}$ for a complete assay, including sample preparation for analysis), this scheme represents a good prototype device for the detection of foodborne pathogens like ST or other immune-responsive bacteria.
\end{abstract}

\section{Introduction}

Keywords:

Potentiometry

Gold nanoparticles

Polymer inclusion membranes

Immunosensor

Salmonella typhimurium
Salmonella is a Gram-negative bacterium from Enterobacteriaceae family and is one of the most important foodborne pathogens that affects human health. Normally, the infection is acquired by ingestion of contaminated food and water [1-3] with rapid dissemination. Several rules and legislation have been applied in most of the developed countries to control the infection prevalence, although the number of cases in some of them is still in a worrying level at a public health scale [4].

The standard methods for S. spp. detection are based on colony counting plate methods which have high sensitivity, but only can give results in 3-7 days after analysis. Other methods, such as enzyme-linked immunosorbent assay (ELISA) and polymerase chain reaction (PCR) commercial kits, have been used in food safety and can reduce the time to obtain definitive results to less than $24 \mathrm{~h}$. Although, to achieve the sensitivity of conventional methods, long pre-concentration and enrichment steps are frequently necessary [5]. Furthermore, some of the commercial rapid methods also require expensive equipment, advanced knowledge and laboratory expertise to conduct the analysis and treat the data. Therefore, simple, rapid and reliable methods for Salmonella control out-of-lab are still necessary in aid to ensure food safety.

In past decades, electrochemical biosensors have drawn increased attention, due to their capability to perform chemical or biological analysis with no considerable sample processing and using simple procedures in a user-friendly interface [6,7]. Additionally, electrochemical transducing techniques enable out-of-lab analysis with high sensitivity. Among electroanalytical techniques, potentiometry with ion selective electrodes (ISE) has recognized merits in the detection of small ionic analytes at low cost and using simple instrumentation $[8,9]$. 
However, for the quantification of large biological species it frequently resorts to nanomaterials to enable and/or to amplify the signal readout, increasing the analysis time and the complexity of the assay [10]. Label-free potentiometric biosensors for bacteria detection are appealing $[11,12]$ but it is necessary to work at low ionic strength because, charged species in the samples may lead to a potentiometric response producing false positive results. Furthermore, these biosensors frequently present a low signal to noise ratio, that makes it impossible to detect very low concentration levels in samples with complex matrix composition as desired in food safety issues [8]. On the other hand, polymeric ion selective electrodes are highly sensitive to changes in zero current ion fluxes across the sensor membrane [13,14]. This characteristic combined with highly specific recognition reactions at the sensor surface has been explored in a few potentiometric sensors based on the blocking surface principle $[8,15,16]$ and offers a route to signal amplification in label-free potentiometric biosensors which has seldom been explored $[17,18]$.

In this work, it is reported the development of a biocompatible platform to be applied as interface in a biosensor device, capable to detect directly antibody-antigen interactions based only on blocking surface principle. The proposed strategy schematized in Fig. 1 integrates an immunosensing interface (IMS), constituted by the bio-receptor immobilized on gold nanoparticles (AuNPs), in a miniaturized ISE responsive to a steady-state concentration of a selected marker ion (not redox active) the sensing membrane vicinity. The application of this label-free potentiometric sensing principle aims to achieve to amplification capabilities close to labelled-based approaches pursuing their sensitivity more simply.

The AuNPs were selected to assemble the IMS due to the wellknown biocompatibility, electrical conducting properties and large surface area [19], which are key factors in label-free designs. Additionally, the possibility of an oriented immobilization of antibodies is also an interesting feature for the development of this immunosensor [20]. The transducer in the proposed biosensor is a ISE with a polymer inclusion membrane (PIM) [21] which is also the support for IMS assembling with the incorporation of AuNPs formed in situ. The basic concept of using PIMs to synthetize metallic nanoparticles monolayers, with a low spent of solvents, is supported in two main steps: the extraction of the interesting ion from a solvent trough a counter ion reaction - mediated by a ion selective membrane - and a reduction step based simply on adding a reducing agent to react with the extracted metal ion or complex [22,23]. The ease of AuNPs synthesis and functionalization and the possibility to control particle size and membrane coverage simply changing the extraction and reduction conditions makes this procedure a versatile approach for IMS assembling and optimization. Additionally, enhanced stability is usually observed for in situ formed nanoparticles [24-26]
Taking this innovative IMS platform, the sensor working mechanism was optimized starting from a zero-current outward flux of marker ion established from the backside of the modified ISE membrane to the sample solution (Fig. 1). After a steady-state condition is reached, the antibody-antigen affinity reaction that occurs at IMS surface will partially block the ion mass transfer to the bulk solution. Upon, this flux is retarded, and the increasing marker ion concentration in aqueous layer unleash a change in the measured electromotive force (EMF) $v s$. an Ag/ $\mathrm{AgCl}$ reference electrode. This effect was accessed over stir studies, during step-by-step IMS construction.

This innovative procedure was successfully tested as a biosensing platform in a pseudo label-free potentiometric immunosensor for Salmonella typhimurium (ST) detection and the analytical performance of several support membrane configurations was evaluated. The IMS were characterized by Scanning Electron Microscopy (SEM), FourierTransform Infrared Spectroscopy-Attenuated Total Reflection (FTIRATR) and its architecture was confirmed with Cyclic Voltammetry (CV) and Electrochemical Impedance Spectroscopy (EIS). As proof-of-concept, recovery studies were performed in spiked commercial apple juice samples.

\section{Experimental}

\subsection{Chemicals and solutions}

S. typhimurium positive control, containing $5 \times 10^{9}$ cell $\mathrm{mL}^{-1}$, was obtained from Kirkegaard \& Perry Laboratories. Anti-Salmonella monoclonal antibodies (Ab), specific for $S$. typhimurium $[27,28]$, were purchased from Santa Cruz Biotechnology.

2-nitrophenyl octyl ether (NPOE), di(n-octyl) phthalate (DOP), methyltrioctylammonium chloride (TOMA), bovine serum albumin (BSA), sodium dihydrogenphosphate monohydrate, potassium dihydrogen phosphate, hydrochloric acid, sodium tetraphenylborate (TPB) and $\mathrm{Na}_{2}$ EDTA were from Sigma Aldrich. Polyvinyl chloride (PVC) was purchased from Fluka and hydrogen tetrachloroaurate (III) trihydrate 99.9\% was obtained from Alfa Aesar. All other reagents were proanalysis quality (pa) or equivalent and were used as received.

The sensor cocktails were prepared by mixing the ion-exchanger (TOMA, $1 \mathrm{wt} \%$ ), the plasticizer (DOP or NPOE, $66 \mathrm{wt} \%$ ) and PVC (33 wt $\%$ ) dissolved in tetrahydrofuran (THF), that after dried forming the polymer inclusion membrane (PIM) [22].

Phosphate buffered saline (PBS, $0.1 \mathrm{~mol} \mathrm{~L}^{-1}$ phosphate buffer, $\mathrm{pH}$ 7.4) was prepared with $\mathrm{Na}_{2} \mathrm{HPO}_{4}$ and $\mathrm{KH}_{2} \mathrm{PO}_{4}$ with or without $25 \mathrm{mmol} \mathrm{L}^{-1} \mathrm{NaCl}$. A pH 7.0 phosphate buffer solution (PB) was also prepared adjusting the $\mathrm{pH}$ of a $0.01 \mathrm{~mol} \mathrm{~L}^{-1} \mathrm{NaH}_{2} \mathrm{PO}_{4}$ with $1 \mathrm{~mol} \mathrm{~L}^{-1}$ $\mathrm{NaOH}$.

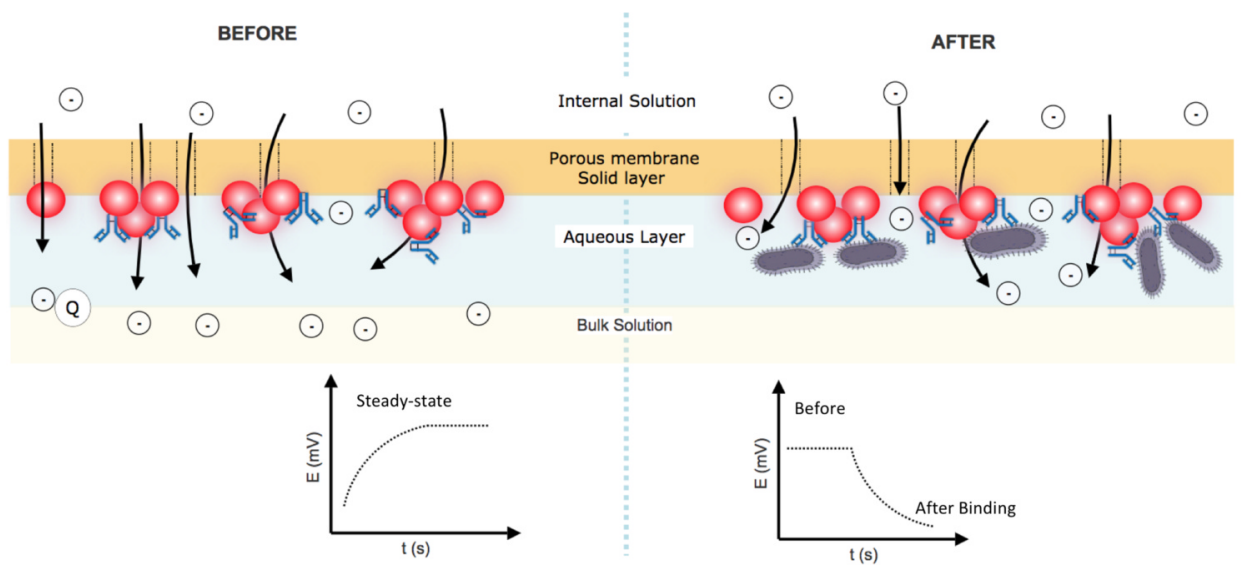

Fig. 1. Schematic representation of surface blocking effect detection mechanism in the developed immunosensing interface. 


\subsection{Fabrication of the immunosensor}

The PVC membrane electrodes $(\varnothing 1.5 \mathrm{~mm})$ were constructed in $5000 \mu \mathrm{L}$ pipette tips, cut to a final height c.a. $45 \mathrm{~mm}$, and cleaned by dipping twice in THF. After solvent removal, they were immersed in the sensor cocktail, which due to intrinsic capillarity filled the tips until approximately the same height $(\approx 5 \mathrm{~mm})$. The membranes were obtained upon THF evaporation at room temperature, shielded from light in a laboratory closet (SI Fig, S1.1).

The AuNPs-PIM formation procedure was adapted from [22,23,29] and optimized to develop a biocompatible platform. The extraction of $\mathrm{Au}(\mathrm{III})$ to the just dried PVC membrane was performed in $5 \mathrm{~mL}$ eppendorf tubes containing $2.5 \mathrm{~mL}$ of $\mathrm{HAuCl}_{4} \cdot 3 \mathrm{H}_{2} \mathrm{O} 100 \mathrm{mg} \mathrm{L}^{-1}$ in a $2.5 \mathrm{~mol} \mathrm{~L}^{-1} \mathrm{HCl}$ solution. During the extraction step, the electrodes were shaken on an orbital mixer at $150 \mathrm{rpm}$ under controlled temperature (at $25^{\circ} \mathrm{C}$ ). Then the electrodes were immersed in $2.5 \mathrm{~mL}$ of $0.1 \mathrm{~mol} \mathrm{~L}^{-1}$ EDTA with pH adjusted to 6,7 , or 8 , and allowed to reduce the extracted $\mathrm{Au}(\mathrm{III})$ under the same previous extraction conditions during $24 \mathrm{~h}$ (SI Fig. S1.2). Between gold complex extraction and reduction steps, the electrodes were washed twice with distilled water (SI Fig. S1.2). All glassware used in the procedures was cleaned with aquaregia and rinsed three times in ultrapure water.

Antibody assembling on AuNPs-PIM was performed by drop-casting $10 \mu \mathrm{L}$ of antibody solution (diluted $1 / 100$ in PBS with $2.5 \mathrm{mmM} \mathrm{NaCl}$ ) directly to the washed and dried AuNPs-PIM electrode surface. It was left in contact in a humid atmosphere overnight at $4{ }^{\circ} \mathrm{C}$. After, the obtained immunosensors (Ab/AuNPs-PIM) were rinsed with PBS and water to remove the not immobilized antibodies and the sensors were stored at $4{ }^{\circ} \mathrm{C}$ in a humid atmosphere until further use. After antibody immobilization some biosensors were also treated with $10 \mu \mathrm{L}$ of BSA solution (10 $\left.\mathrm{mg} \mathrm{mL}^{-1} ; 1 \mathrm{~h}\right)$ (SI Fig. S7.1).

Finally, the electrodes were filled with a TPB solution $\left(10 \mathrm{mg} \mathrm{mL}^{-1}\right.$ in PB) and placed in a moist atmosphere at $4{ }^{\circ} \mathrm{C}$ during the conditioning treatment and when they were not in use. For the potentiometric measurements, homemade $\mathrm{Ag} / \mathrm{AgCl}$ electrodes [30] were used as inner reference in the pipette tip biosensors. A schematic representation of the procedure was detailed in Supporting information (SI Fig. S1.1).

The optimization of sensor and internal solution composition to achieve a reliable and reproducible passive ion flow is described in the Supplementary material S2.

\subsection{Immunosensing interface characterization}

\subsubsection{Scanning electron microscopy}

SEM studies were carried out at CEMUP (Centro de Materiais da Universidade do Porto), Porto, Portugal. SEM images were obtained with a scanning electron microscope Quanta 400 FEG scanning electron microscope, (SEM, FEI, Hillsboro, OR), operated in high vacuum/secondary electron imaging mode using an accelerating voltage of $15 \mathrm{kV}$ and working distances between 10.3 and $12.4 \mathrm{~mm}$. The AuNPs-PIM films were assembled on aluminum stubs covered with carbon adhesive tabs (Electron Microscopy Sciences, Hatfield, PA). The AuNPs penetration into the PIM was analyzed using fracture images, surface images at both sides of the PIM and lateral secondary electron detector (ETD) configured to backscattered electrons (without bias voltage applied) to give a shadow effect over the polymer surface. ImageJ software was used to study the size distribution and surface morphology of AuNPsPIM.

\subsubsection{Cyclic voltammetry and faradaic impedance measurements}

Cyclic voltammetry (CV) measurements were performed using an electrochemical system (PGSTAT12, Metrohm Autolab) and the potential was swept between -0.2 and $0.6 \mathrm{~V}$ at different scan rates $(5-100 \mathrm{mV} / \mathrm{s})$ in $\mathrm{PBS}$ solution without $\mathrm{NaCl}(\mathrm{pH}$ 7.4) using [Fe $\left.(\mathrm{CN})_{6}\right]^{4-/ 3-}\left(1 \mathrm{mmol} \mathrm{L}^{-1}\right.$ in $\left.0.1 \mathrm{~mol} \mathrm{~L}^{-1} \mathrm{KNO}_{3}\right)$ as redox marker.

Electrochemical impedance spectroscopy (EIS) experiments were performed with an Autolab Electrochemical Analyzer (PGSTAT128N, Metrohm). All tests were conducted at an open circuit, recorded for 75 data points, at a single modulated AC potential of $+0.375 \mathrm{~V}$ with frequency ranging between $10 \mathrm{mHz}$ and $100 \mathrm{kHz}$.

The General Purpose Electrochemical System (GPES, version 4.9) software from Metrohm was used to control the system and process the CVs. To obtain and process the EIS spectra the NOVA (version 1.7) software also from Metrohm Autolab was used.

All these experiments were made in a one-compartment threeelectrode cell system comprising a bare or modified glassy carbon (GCE, $\varnothing 3 \mathrm{~mm}$ ) working electrode, an $\mathrm{Ag} / \mathrm{AgCl}\left(\mathrm{KCl} 3 \mathrm{~mol} \mathrm{~L}^{-1}\right)$ reference electrode and a platinum wire counter electrode, all from Metrohm.

\subsection{Potentiometric measurements towards Salmonella typhimurium}

The EMF was measured with an EMF16 Interface from Lawsons Labs and the potentiometric cell was in a faraday cage. A double junction reference electrode (Orion 90-02-00) from Thermo Scientific Orion and a magnetic micro-stirrer from Velp Scientifica were used. All measurements were made in PB buffer, stirred at $150 \mathrm{rpm}$ and at room temperature.

The potentiometric response of the immunosensor towards ST was based on the change of EMF before and after antigen-antibody reaction [18]. Control and real sample evaluation were performed subtracting the steady-state EMF value measured in a blank solution (PB, $\mathrm{pH} 7$ ) to the EMF value in the presence of a certain amount of ST cells or nonspiked solutions (positive control or negative controls). The calibration curves were obtained by standard addition method, and the EMF was calculated subtracting the steady-state value of EMF in PB to the values registered after each addition and presented as average responses associated to the respective standard deviation of three different intraassay replicas.

Fig. 1 is a schematic representation of the mechanism of detection of ST were the shift of EMF is originated by the resistance to mass transport of the marker ion provoked by the immunobinding on the membrane surface.

\subsection{Analysis of apple juice samples}

As a proof of concept artificially contaminated apple juice samples, purchased in a local supermarket, were examined with the developed biosensor. The samples were diluted 1:10 in water and then spiked with different amounts of ST cells, to achieve to a final concentration in the range from 0 (no-spiked sample) to 100 cells $\mathrm{mL}^{-1}$.

A pretreatment protocol, based on simple filtration and elution steps was taken [11]. Briefly, a sterilizing syringe filter $(0.2 \mu \mathrm{m}$ pore size) was used to pull and separate the ST cells from the juice matrix. Then the filter was turned down-side and a controlled volume of PB was injected to elute the cells retained in the filter. Finally, potentiometric detection of the eluate was taken.

\section{Results and discussion}

\subsection{Characterization AuNPs-PIM platform}

The possibility of assembling a stable AuNPs layer on the PIM membrane is a necessary condition for biosensor development. A characteristic of the selected method for in situ AuNPs synthesis is the possibility to control the shape, size, location (within or on the membrane surface) and the extent of membrane coverage simply changing the experimental conditions for AuNP synthesis. Different reducing agents have been used for AuNPs preparation [23,31] but in this work it was used $\mathrm{Na}_{2}$ EDTA because it gave rise to membrane surface coverage by the newly formed nanoparticle [29]. As $\mathrm{Na}_{2}$ EDTA oxidation depends on the presence of water, PVC was chosen as polymeric matrix because it is not hydrated and due the polar characteristics of its $\mathrm{C}-\mathrm{Cl}$ functional 

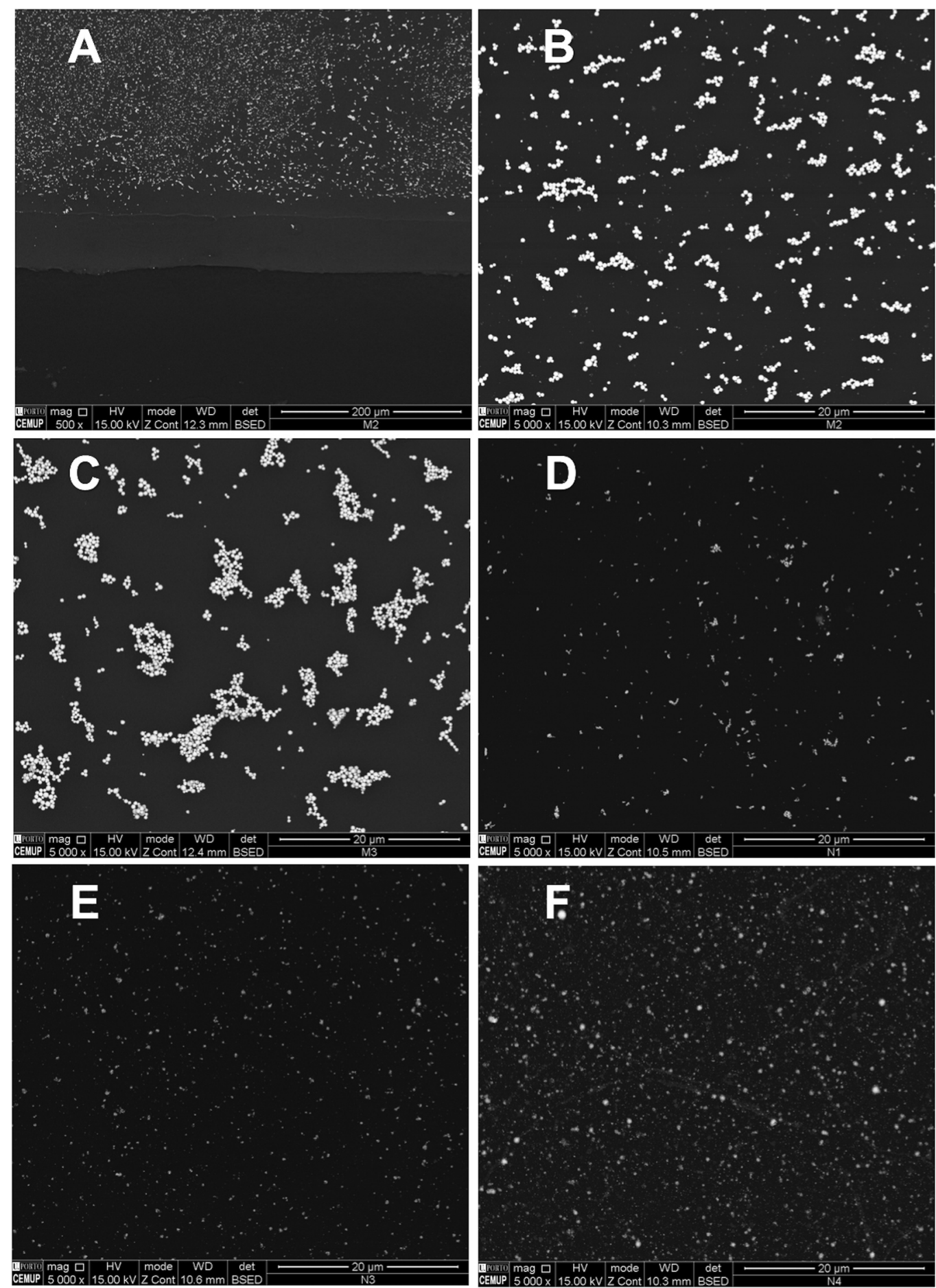

Fig. 2. SEM images of gold nanoparticles formed on polymer inclusion membranes (AuNPs-PIM) with different protocols using $0.1 \mathrm{~mol} \mathrm{~L}^{-1} \mathrm{Na}_{2} \mathrm{EDTA}$ for Au(III) reduction:(A and B) cross section and surface of a PIM membrane with AuNPs obtained with $1 \mathrm{~h}$ extraction of tetrachloroaurate(III) and $30 \mathrm{~h}$ of reduction at $\mathrm{pH} 6$; (B) magnification of image A; (C) $2 \mathrm{~h}$ of extraction and $30 \mathrm{~h}$ reduction at $\mathrm{pH}$ 6. (D, E and F) Surface images of AuNPs-PIM for $1 \mathrm{~h}$ of extraction and $24 \mathrm{~h}$ of reduction at $\mathrm{pH}$ 6 (D), pH 7 (E); and pH 8 (F).

group [22]. The cross-section image in Fig. 2 A shows that using $\mathrm{Na}_{2}$ EDTA as the reducing reagent the AuNPs were formed on the PIM surface.

The effect of extraction and reduction time as well as the composition ( $\mathrm{pH}$ and concentration) of the $\mathrm{Na}_{2}$ EDTA solution on the morphology, topology and size of the formed AuNPs were also assessed. The images in Fig. 2 show the effect of experimental conditions on the quantity and quality of the AuNPs produced. Regarding extraction (Figs. 2, $1 \mathrm{~h}(\mathrm{~B})$ and $2 \mathrm{~h}(\mathrm{C})$ ) or reduction time (Fig. 2, $24 \mathrm{~h}$ (D) to $30 \mathrm{~h}$
(B)) it was observed that as the reaction time increases, the amount of grown spherical AuNPs on PIM membrane also increases. A similar effect was observed with increasing $\mathrm{Na}_{2}$ EDTA concentrations $(0.1$ and $0.2 \mathrm{~mol} \mathrm{~L}^{-1}$ ) at pH 6 (Fig. 2 and SI Fig. S3.1).

Employing short reduction time periods ( $1.5 \mathrm{~h}$ and $3 \mathrm{~h}$ ), AuNPs were not formed (data not shown). From SEM images in Fig. 2(D, E and F) it can be observed that the best AuNPs coverage was reached using $0.1 \mathrm{~mol} \mathrm{~L}^{-1} \mathrm{Na}_{2}$ EDTA solutions at $\mathrm{pH} 8$ (using an extraction and reduction time of $1 \mathrm{~h}$ and $24 \mathrm{~h}$ respectively). Although the AuNPs 


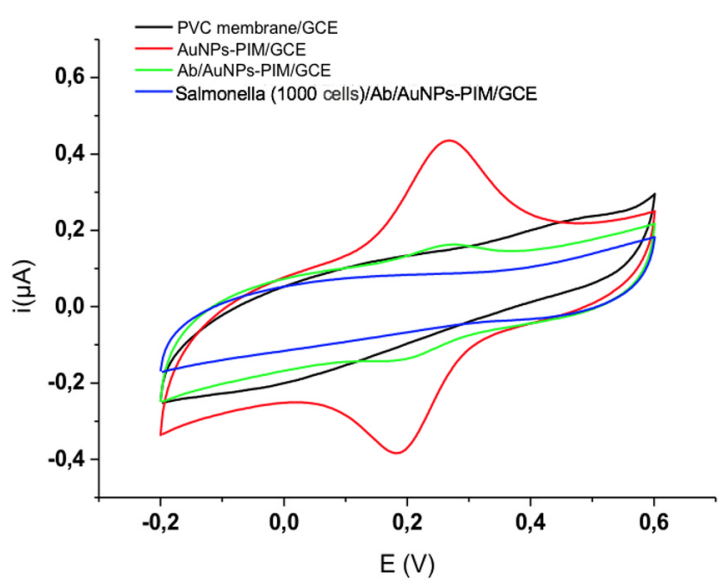

C

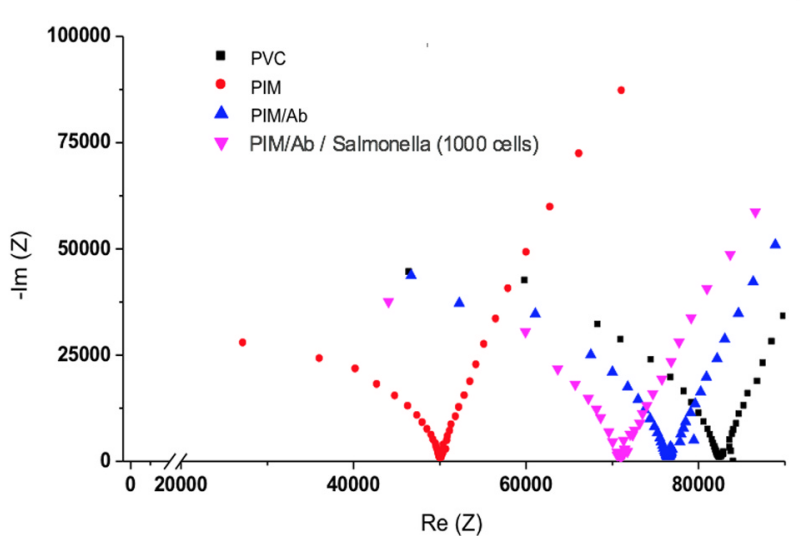

B

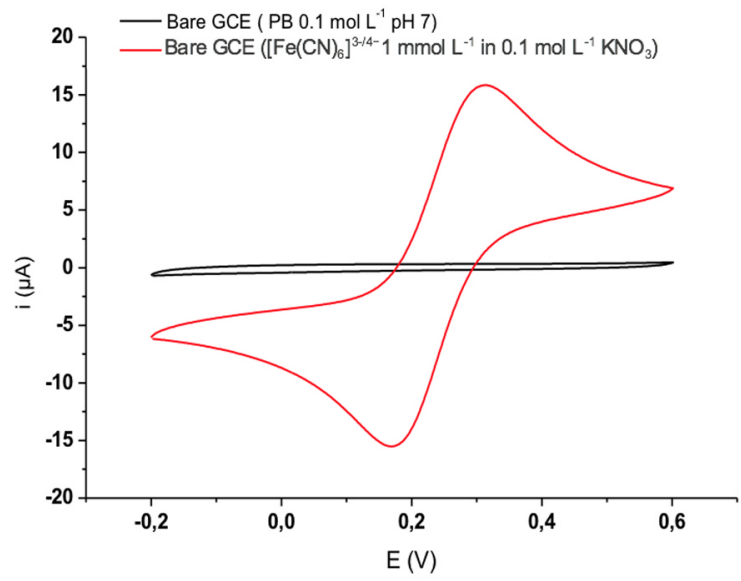

D

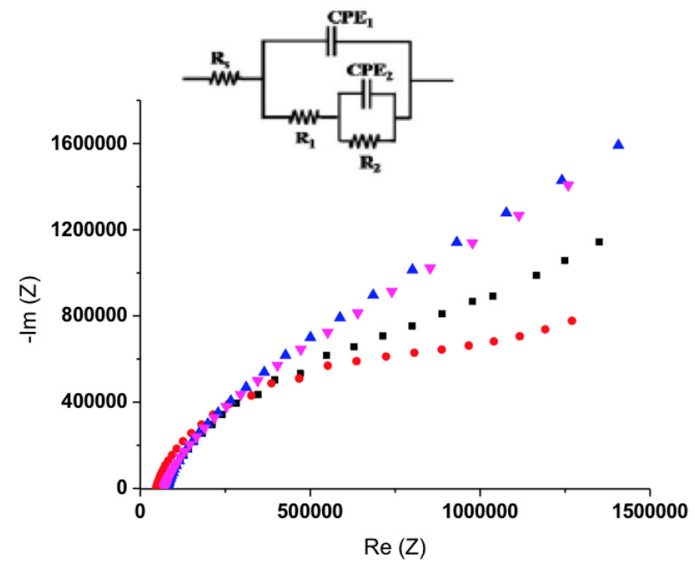

Fig. 3. (A) Cyclic voltammograms of different modified electrodes and; (B) bare electrode in PBS $\left(0.1 \mathrm{~mol} \mathrm{~L}^{-1} \mathrm{pH} 7.4\right.$, without $\left.\mathrm{NaCl}\right)$ and in $1 \mathrm{mmol} \mathrm{L}-1$ [Fe(CN) $]^{3-/ 4-}$ solution probe with $\mathrm{KNO}_{3} 0.1 \mathrm{~mol} \mathrm{~L}^{-1}$ as support electrolyte. (C and D) Nyquist plots of EIS at high (C) and low frequencies (D): PVC membrane/GCE (black square); AuNPs polymer inclusion membrane PIM/GCE (red circle); Antibody anti-Salmonella loaded into AuNPs-PIM (Ab/PIM/GCE) (blue triangle) and; after incubation of Ab/ PIM/GCE with Salmonella (1000 cells) (pink triangle); all in $0.1 \mathrm{~mol} \mathrm{~L}^{-1} \mathrm{KNO}_{3}$ containing $2.5 \mathrm{mmol} \mathrm{L}^{-1}$ of $\left[\mathrm{Fe}(\mathrm{CN})_{6}\right]^{3-/ 4}$ probe; electric circuit representative of the developed IMS into a GCE electrode (inset in the figure). (For interpretation of the references to colour in this figure legend, the reader is referred to the web version of this article.)

presented as clusters of closely packed particles having a highly irregular shape comparing to $\mathrm{pH}$ 's 6 and 7.

Particle size was also evaluated processing the SEM images with ImageJ software and the corresponding histograms (SI Fig. S3.2) showed that with $\mathrm{Na}_{2}$ EDTA $0.1 \mathrm{~mol} \mathrm{~L}^{-1}$ at pH 6 the obtained AuNPs size were $229 \pm 87 \mathrm{~nm}$ and $357 \pm 89 \mathrm{~nm}$ for $24 \mathrm{~h}$ and $30 \mathrm{~h}$ reduction time respectively. These particle sizes are clearly beyond the nanoscale materials, with properties closer to metallic gold. Increasing the concentration of $\mathrm{Na}_{2}$ EDTA to $0.2 \mathrm{~mol} \mathrm{~L}^{-1}$ the particles diameter diminished considerably to $41 \pm 14 \mathrm{~nm}$ of diameter but increasing polydispersity was also observed. The increase of $\mathrm{pH}$ of the reduction reaction also produced nanoscale particles with diameters of $44 \pm 13 \mathrm{~nm}$ and $28.5 \pm 8 \mathrm{~nm}$ at $\mathrm{pH} 7$ and 8 respectively.

\subsection{Optimization of IMS}

The response towards Salmonella was evaluated to assess the effect of different IMS configurations with the AuNP monolayer on the sensor surface. The experimental results show that the amplitude of the immunosensor response to ST decreased (SI Fig S4.1A) as extraction time of $\mathrm{Au}(\mathrm{III})$ to the PVC membrane increased $(0.5-3 \mathrm{~h})$, suggesting that increasing this experimental parameter produced a higher amount of AuNPs and a more effective barrier to the marker ion diffusion from the membrane to the bulk solution (Fig. 2B and D).
A reduction time of $24 \mathrm{~h}$ was already assumed by other authors as optimal to obtain good surface coverage by AuNPs [29]. Indeed, no improvement in potentiometric response was observed when longer reduction times were employed. Although an amplification of the signal was observed but the reproducibility between electrodes response was poor (SI Fig. S4.1B). Correlating these results with the SEM images an increase in the number of AuNPs in large agglomerates (Fig. 2C and D) and an increase in average AuNPs diameter (SI Fig. S3.2) and polydispersity was observed upon increasing reduction time.

Similarly, in the potentiometric study of the effect of the $\mathrm{Na}_{2}$ EDTA solution $\mathrm{pH}$, the electrodes subjected to a reduction step at $\mathrm{pH} 7$ showed the best performance as compared with similar sensors involving the $\mathrm{Au}$ (III) reduction at $\mathrm{pH} 6$ or 8 (SI Fig. S4.2).

Based on these observations we can assume that the presence of irregular and agglomerated distribution of AuNPs were decisive in the effectiveness degree of antibody load and consequently antigen conjugation.

Considering the antibody size [32], usually 10-15 nm, an AuNPs size of $52 \pm 14 \mathrm{~nm}$ was chosen to reduce the immobilized antibody steric hindrance and AuNPs aggregation. This optimum particle size corresponded to extraction during $1.5 \mathrm{~h}$ and reduction with $0.1 \mathrm{~mol} \mathrm{~L}^{-1}$ $\mathrm{Na}_{2}$ EDTA at $\mathrm{pH} 7$ for $24 \mathrm{~h}<$ Furthermore, particles prepared under these conditions showed moderate polydispersity and good coverage of the polymeric membrane (c and d in SI Fig. S3.1). 
After antibody immobilization some electrodes were treated with BSA. The signal of the BSA modified electrodes was amplified at least four times, although the response relative standard deviation between electrodes was worse (SI Fig. S7.1). The oriented conjugation of BSA and its negative charge contribution to membrane potential at neutral $\mathrm{pH}$ can explain the signal amplification. Therefore, its presence also can hide some antibody active spots and increase the steric hindrance between them [33]. Because of the duality of the effect of the BSA, this modification step was excluded in further experiments, considering the pretreatment protocol used (see Section 2.5), which excludes in advance the presence of common interferers, and consequently non-specific interactions with AuNPs.

\subsection{IMS characterization}

\subsubsection{Cyclic voltammetry}

An electrochemical study using the $\left[\mathrm{Fe}(\mathrm{CN})_{6}\right]^{3-/ 4-}$ redox couple as molecular probe was performed to observe and characterize the surface changes of different layers immobilized onto GCE. Fig. 3(A and B) shows $\mathrm{CVs}$ of $\left[\mathrm{Fe}(\mathrm{CN})_{6}\right]^{3-/ 4-}$ after each assembly step. As it is possible to verify, when it was used a bare GCE a redox peak was observed whose anodic peak potential $\left(\mathrm{E}_{\mathrm{pa}}\right)$ was $+0.32 \mathrm{~V}$ with a peak intensity of $15.83 \mu \mathrm{A}$ and a cathodic peak potential $\left(\mathrm{E}_{\mathrm{pc}}\right)$ at $+0.17 \mathrm{~V}$ with a peak intensity of $-15.5 \mu \mathrm{A}$. A good reversibility with a peak to peak separation of $0.15 \mathrm{~V}$ was observed. The same experiment was performed using a PIM/GCE and a displacement of the $\left[\mathrm{Fe}(\mathrm{CN})_{6}\right]^{3-/ 4-}$ redox potential to more positive values was observed $\left(\mathrm{E}_{\mathrm{pa}}\right.$ at $\left.+0.60 \mathrm{~V}\right)$, furthermore a $98 \%$ reduction of electrochemical signal $\left(i_{\mathrm{pa}}\right.$ decreased to $0.3 \mu \mathrm{A}$ ) was obtained, exhibiting an irreversible response. These results clearly demonstrate that the PIM was effectively immobilized onto GCE surface and it blocks the diffusion of the redox couple towards the GCE surface and drastically decreased the current response. The slight diffusion rate of the $\left[\mathrm{Fe}(\mathrm{CN})_{6}\right]^{3-/ 4-}$ from the solution to the electrode surface was probably promoted by the anionic exchanger in the PVC membrane.

However, when AuNPs were assembled onto PVC/GCE (AuNPsPIM/GCE), the $\mathrm{E}_{\mathrm{pa}}$ of $\left[\mathrm{Fe}(\mathrm{CN})_{6}\right]^{3-/ 4-}$ shifted to $+0.27 \mathrm{~V}$ with an $\mathrm{i}_{\mathrm{pa}}$ of $0.435 \mu \mathrm{A}$. The observed increase of the $i_{\text {pa }}$ as compared to the PVC/GCE electrode was attributed to an increase in surface area, promoted by the AuNPs, which enhance the electron transference rate and promoted a slight increase of the diffusion rate of the redox couple from the electrolyte to the electrode surface. In AuNPs-PIM configuration the kinetics of charge transfer was independent of the thickness of the modification layer on the GCE. In the cases of partially or almost complete coverage/blockage of the electrode surface like Ab/AuNPsPIM/GCE or Salmonella/Ab/AuNPs-PIM/GCE, this effect is significant, and the maximum current intensity decreases proportionally to the thickness increasing of the modification layer. Specifically, after antibodies adsorption the anodic peak intensity reduce almost $63 \%$ comparing with AuNPs-PIM/GCE, corresponding to almost 99\% of electrochemical signal reduction (bare GCE), confirming the antibody assembling.

\subsubsection{Electrochemical impedance spectroscopy}

EIS technique employing $\left[\mathrm{Fe}(\mathrm{CN})_{6}\right]^{3-/ 4-}$ redox couple as probe $(2.5 \mathrm{mM})$ was used to characterize and verify layer by layer the efficiency of the electrode modification, such as some information about electrode surface electron transfer kinetics. These electrochemical responses were obtained through the differences in electron-transfer rate, diffusion limited process and double-layer capacitance in electrode/ redox probe solution interface between the different assembling steps.

Fig. 3(C and D) represents the real and imaginary impedances plotted against each other in a Nyquist plot representation. The several figures correspond to the different electrode modification steps, showing two distinct frequency regions. The semicircle portion, which was observed at higher frequencies Fig. 3(C), was associated with a process that was limited by electron transfer at the electrodes surface. The linear features observed at lower frequencies Fig. 3(D) were attributed to diffusion-limited electron transfer [34]. It was observed a high increase in the resistance to the electron transfer, due to the PIM layer (a non-conductive hydrophobic polymer) onto GCE [35]. The drop-cast of the plasticized membrane creates an insulation layer on GCE interface, although as it was observed in the CV only partial blocking of electron transference was verified. A small redox peak can be seen in this specific modification step plot after some time immersed in the probe solution. In this case the electron transfer rate is limited at first by the slow diffusion of the electrolyte solution trough the PIM plus next step modifications and by the decreasing of active spots on GCE surface. Some PIM membrane show micropores which act as small double capacitive layers in parallel with expected kinetically controlled charge-transfer reaction [36,37] (SI Fig. S3.1g).

In the high frequency region Fig. $3 \mathrm{C}$, it can be noted too that the initial part of semicircle disappears when the PIM was introduced on the GCE surface and can be attributed to a combined effect of the charge-transfer resistance at GCE electrode interface and the doublelayer capacitance [38]. This is characteristic of the presence of a nonperfect capacitor and another constant phase element (CPE) like the Open Finite-Length Diffusion (OFLD) in the electric circuit model (inset of Fig. 3 D) $[36,37]$.

So, as the modification layers' thickness increases, the time required to obtain the first visible register in our circuit model (AC voltage $=+$ $0.375 \mathrm{~V}$ ), should also increase if the electrode reaction occurs only at the bare spots on the electrode surface. In this model, the chargetransfer resistance is intrinsically connected with the resistance of ionconducting (pore resistance). Although when AuNPs were assembled, the resistance decreases comparing to the previous configuration. The phenomenon can be explained by the capacity of nanoparticles create electron-conducting tunnels and their electrocatalytically properties, enhancing the transference of electrons [16]. Parallel to this, the diffusional part of the plot (straight line), presents a squeezed depressed semicircle in the PIM configuration, which was associated to the negative net charge of AuNPs (see SI section S6) that increases the [Fe $\left.(\mathrm{CN})_{6}\right]^{3-/ 4-}$ solution charge repulsion $[39,40]$. The immobilization of antibody IgG anti-ST results in a significant increase of total resistance due the formation of an additional insulating layer on the electrode surface. With the insertion of the ST antigen the resistance decreases, contrariwise what was expected, hypothetically due the more oriented and surface detached position of the ST-Ab immune-complexes that can facilitate the diffusion of the ions to the GCE [41]. This phenomenon is according the literature, for other biomolecules specially the ones conjugated by physical adsorption [42,43]. Additionally, in these two last approaches the diffusion limited process is represented mostly as a straight line. According to previous results, it can represent the neutralization of carboxylic group's negative charges presents at the AuNPs-PIM membrane and homogenization of electrode surface by antibody adsorption.

\subsection{Immunosensor performance}

It was clear that the hydrophilic AuNPs layer formed on the PVC membrane electrode enhances the potentiometric signal, probably by the enlargement of the electrode surface area, ordered antibody density and tunneling effect [16]. As suggested from electrochemical characterization of the IMS, the AuNPs grow preferably close to the membrane pores $[29,44]$, so the antibody load and the immunocomplex formation occurs mainly close to the electrode active spots, amplifying the blocking effect caused by the phenomena, and consequently the immunosensor sensitivity $[15,16]$.

The dynamic potentiometric response curves of the immunosensors presented in Fig. $4 \mathrm{~A}$ were obtained upon successive additions of ST standard solutions $\left(10^{4}, 10^{6}, 10^{8}\right.$ cells $\left.\mathrm{mL}^{-1}\right)$ to a stirred PB matrix, after a steady-state potential was achieved. These curves illustrate the 

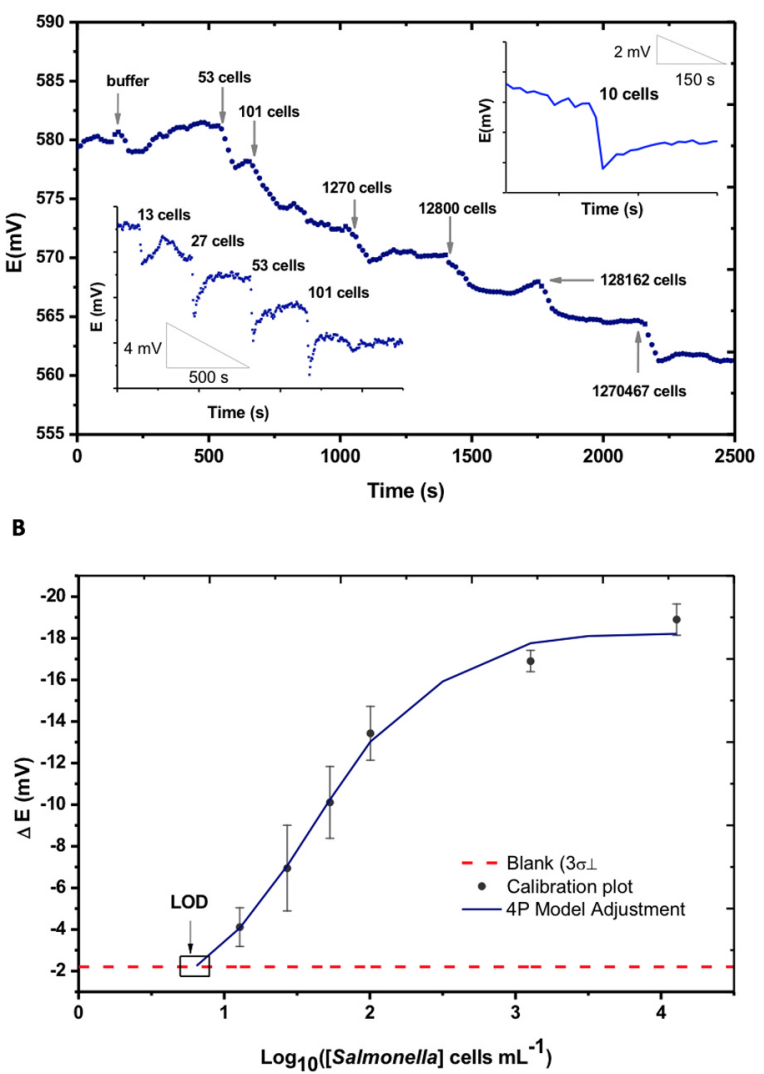

Fig. 4. A) Typical dynamic response curves of the immunosensors obtained in PB $0.01 \mathrm{M} \mathrm{pH} 7$ for $S T$ in response to the indicated concentrations expressed in cells $\mathrm{mL}^{-1}$; B) Calibration plot (potential difference in reason of the log of $S T$ concentration) in PB $0.01 \mathrm{M} \mathrm{pH} 7$ showing the response of three different electrodes constructed in the same conditions $(n=3)$. Baseline and standard deviation (solid and dashed red lines. Error bars indicate the standard deviation of the three immunosensors assayed. (For interpretation of the references to colour in this figure legend, the reader is referred to the web version of this article.)

effect of increasing surface blocking upon ST binding to the IMS on the TPB flow from the internal to the bulk solution. A extrapolating from Fick's first law, shows that once steady-state was achieved, -that is the outward flux trough ISE membrane, the diffusional layer closer to IMS surface and thought the aqueous are the same, - any potential changes that arises is due to differences in diffusion and binding layer (named all as aqueous layer, Fig. 1) or surface-confined layer thickness and respective diffusion coefficients [17]. Taking this appointment, it was expected that the signal attenuation that coming from convective stirring was compensated by large Salmonella size (lengths from 2 to $5 \mu \mathrm{m}$ ). The immunosensors show a rapid response and upon addition of the ST cells a stable response is observed in less than $10 \mathrm{~min}$.

In Fig. 4B the relation of EMF difference and the logarithm of ST concentration was represented. The response curve shows a sigmoidal shape as is frequently observed in biological processes. A calibration curve (black dashed line in Fig. 4B) was calculated using the fourparameter (4 P) regression model [45], quite used in biological receptor-ligand binding assays $[46,47]$. The calculated detection limit (set out by Eq. 1 ( $n=3,6$ replica each)) of the developed immunosensor was 6 cells $\mathrm{mL}^{-1}$.

$L O D=x\left(\frac{a-d}{(a-d)-3 \sigma}-1\right)^{-1 / k}$

Comparing with other electrochemical label-free immunosensors in the literature (Table 1) we achieved to a very good LOD, even some of them accomplished lower values $[11,48,49]$. Specifically, ZeladaGuillén et al. (2009) and Ranjbar et al. (2018) works reported LODs as low as 1 cell $\mathrm{mL}^{-1}$ that was aligned to the legislated limits. Although, in Zelada-Guillén et al. (2009) work a low ionic strength media was needed to perform the analysis and the method applicability to real samples was not stated. Instead, Ranjbar et al. (2018) presented the applicability test in a complex sample, despite the multi-step sample preparation and the high contamination levels tested. Likewise, the assumed LOD was quite far from the lower limit of the linear range, increasing the uncertainty at low contamination levels. Nevertheless, biosensors presenting a LOD much lower than the infection levels for ST (1000 cells $\mathrm{mL}^{-1}$ ), may be useful for screening purposes or as confirmation test of infection in human.

\subsubsection{Regeneration and stability of the immunosensor}

Reusing of an immunosensor is very appealing due the possibility of application to many samples in a short period at a low cost relatively to the disposable ones [54]. Accordingly, several regeneration reagents which have already been successfully used by Park et al. [55].in 2000 were tested. After the regeneration step, the immunosensor response

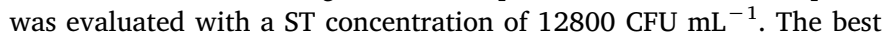
results were achieved using glycine- $\mathrm{HCl} 0.1 \mathrm{M} \mathrm{pH} 2$ but the response of the immunosensor after the third cycle of regeneration drop to $53 \%$ of initial value.

Table 1

Label-free electrochemical biosensors for Salmonella spp. detection.

\begin{tabular}{|c|c|c|c|c|c|c|c|}
\hline Transducer & Nanomaterial & $\begin{array}{l}\text { Detection } \\
\text { Technique }\end{array}$ & Working range & LOD & Analysis Time & Sample & Refs. \\
\hline $\begin{array}{l}\text { Double-Walled } \\
\text { Electrode }\end{array}$ & CNTs & $\mathrm{CA}$ & $10^{2}-10^{7}$ cells $\mathrm{mL}^{-1}$ & 8.9 cells $\mathrm{mL}^{-1}$ & Total $\cong 6 \mathrm{~h}$ & PBS & {$[48]$} \\
\hline GCE & MSNTs & I & $10^{3}-10^{7}$ cells $\mathrm{mL}^{-1}$ & $\begin{array}{l}5 \times 10^{2} \text { cells } \mathrm{mL}^{-1} \text { in } \\
\text { PBS }\end{array}$ & $30 \mathrm{~min}$ & PBS & {$[50]$} \\
\hline GE & - & EIS & - & 500 cells $\mathrm{mL}^{-1}$ & Total of $6 \mathrm{~min}$ & PBS & [51] \\
\hline GCE & AuNPs MWCNTs & I & $10^{3}-10^{7}$ cells $\mathrm{mL}^{-1}$ in PBS & $\begin{array}{l}500 / 1000 \text { cells } \mathrm{mL}^{-1} \\
\text { in } \mathrm{PBS} / \mathrm{milk}\end{array}$ & About $1 \mathrm{~h}$ & PBS Milk & [52] \\
\hline SPE & - & EIS & $10^{3}-10^{8}$ cells $\mathrm{mL}^{-1}$ & $10^{3}$ cells $\mathrm{mL}^{-1}$ & $\begin{array}{l}\text { Total } \cong 16.5 \mathrm{~h} \\
\text { Analysis- } 20 \mathrm{~min}\end{array}$ & PBS Milk & [53] \\
\hline GCE & SWCNT & $\mathrm{P}$ & $0.2-10^{3}$ cells $\mathrm{mL}^{-1}$ & 1 cell mL $^{-1}$ & $1 \mathrm{~min}$ & PBS & [11] \\
\hline GCE & Nanoporous gold & EIS & $6.5 \times 10^{2}-6.5 \times 10^{8}$ cells $\mathrm{mL}^{-1}$ & 1 cell $\mathrm{mL}^{-1}$ & About $40 \mathrm{~min}$ & PBS Eggshell & [49] \\
\hline ISE & AuNPs & $\mathrm{P}$ & $13-1.3 \times 10^{6}$ cells $\mathrm{mL}^{-1}$ & 6 cells $\mathrm{mL}^{-1}$ & $\begin{array}{l}\text { About } 1 \mathrm{~h} \text { for a } \\
\text { complete assay }\end{array}$ & $\begin{array}{l}\text { PB Apple } \\
\text { juice }\end{array}$ & This work \\
\hline
\end{tabular}

Glassy Carbon Electrode (GCE); Gold Electrode (GE) Impedimetry (I); Magnetic silica nanotubes; (MSNTs); Single-walled. Carbon nanotubes(SWCNT); Multi-walled carbon nanotubes (MWCNTs); Potentiometry (P); Chronoamperommetry (CA). Screen-printed electrode (SPE). 
Table 2

Recovery (\%) of Salmonella typhimurium (10, 75 and 100 cells $\mathrm{mL}^{-1}$ ), in commercial apple juice samples.

\begin{tabular}{llll}
\hline \multirow{2}{*}{$\begin{array}{l}\text { Theoretical concentration } \\
\text { (cells } \mathbf{~ m L}^{-\mathbf{1}} \text { ) }\end{array}$} & \multicolumn{2}{l}{ Recovery (\%) } \\
\cline { 2 - 4 } & $\mathbf{n}$ & Mean \pm SV & Coef. V (\%) \\
\hline 10 & 3 & $72.9 \pm 1.0$ & $1.3 \%$ \\
75 & 3 & $80.6 \pm 1.6$ & $2 \%$ \\
100 & 3 & $40.4 \pm 2.0$ & $5 \%$ \\
Mean & - & $64.6 \pm 0.5$ & $2.8 \%$ \\
\hline
\end{tabular}

Mean $\pm \mathrm{SV}=$ mean \pm standard deviation of three replicates.

Coef. $\mathrm{V}=$ coefficient of variation; $\mathrm{n}=$ number of samples.

The immunosensor stability was tested along the time by the calibration of immunosensors with different lifetime after construction. The storage was made without internal solution, at $4{ }^{\circ} \mathrm{C}$ in hydrated atmosphere until use. After 10 days storage a decay to a third of the initial response $(34 \%)$ was observed.

\subsection{Apple juice sample analysis}

The results obtained in the analysis of samples with 10, 75 and 100 $\mathrm{CFU} \mathrm{mL}{ }^{-1}$ of ST were correlated with the calibration curve performed in PB. The respective recoveries $\%$ are shown in Table 2 .

The average recovery of ST was consistent in the range of concentrations $10-100 \mathrm{CFU} \mathrm{\textrm {mL } ^ { - 1 }}$ with an average value of 64.6. Despite the low recovery rates achieved, the method reveals a good interassay precision with a Coef.V $(\%) \leq 5$, demonstrating the applicability of the developed immunosensor for screening purposes at low ST concentration. As prospects to optimize the quantification potential of the developed immunosensor in foodstuffs with complex matrix, without a significant increase of the total time of analysis, it is worth couple the immunosensor to immunomagnetic separation methods.

\section{Conclusions}

AuNPs formed in-situ on a PIM has been successfully used as a biocompatible sensing platform for bioreceptor conjugation and the developed IMS also promoted the amplification of the measured potentiometric signal in a label free biosensor with sensitivity close to labelled approaches. The proposed label-free potentiometric immunosensor shows potential for on-site food control owing to the easiness of the experimental procedure and the simplicity and portability of the potentiometric instrumentation. A more effective separation method, such as an immunomagnetic separation can be applied to magnify the recovery of the immunological assay, to be applied to complex matrixes. At this point the developed immunosensor can be a simple, low-cost, disposable and useful tool for screening of ST in food and water samples. The proposed potentiometric immunosensor stands out from its conventional counterparts because it combines the feasibility of miniaturized polymer membrane ISE and the specificity of surface confined immune reactions to assemble a robust and sensitive immunosensor without labels and resorting to a simple instrumentation.

Since the signal amplification was obtained through the developed IMS, without resorting to redox labels or enzymatic amplification, this reliable method can be easily applied to different bacteria-antibody couple, simply changing the specific antibody and optimizing the AuNP-PIM. Furthermore, the strategy presented in this work shows potential for application to other bioreceptors as it allows to control, particle size distribution and membrane surface coverage and the selectivity of the PIM sensor towards the selected marker ion allows working in several biological $\mathrm{pH}$ buffers.

\section{Acknowledgments}

This work received financial support from the European Union (FEDER funds through COMPETE) and National Funds from Portugal; FCT-Fundação para a Ciência e a Tecnologia through projects UID/QUI/50006/2013 and Norte-01-0145-FEDER-000011-RL1QUALIFOOD. N.F.D Silva and M.F. Barroso are gratefully to FCT grant SFRH/BD/112414/2015 and SFRH/BPD/78845/2011, financed by POPH-QREN-Tipologia 4.1-Formação Avançada, subsidized by FSE and MCTES.

\section{Associated content}

Supporting information. Detailed information about the fabrication optimization and characterization of the developed immunosensor.

\section{Appendix A. Supplementary material}

Supplementary data associated with this article can be found in the online version at doi:10.1016/j.talanta.2018.10.024.

\section{References}

[1] S. Chemburu, E. Wilkins, I. Abdel-Hamid, Detection of pathogenic bacteria in food samples using highly-dispersed carbon particles, Biosens. Bioelectron. 21 (3) (2005) 491-499.

[2] F. Farabullini, F. Lucarelli, I. Palchetti, G. Marrazza, M. Mascini, Disposable electrochemical genosensor for the simultaneous analysis of different bacterial food contaminants, Biosens. Bioelectron. 22 (7) (2007) 1544-1549.

[3] K.-M. Lee, M. Runyon, T.J. Herrman, R. Phillips, J. Hsieh, Review of Salmonella detection and identification methods: aspects of rapid emergency response and food safety, Food Control 47 (2015) 264-276.

[4] EFSA, The European Union summary report on trends and sources of zoonoses, zoonotic agents and food-borne outbreaks in 2016, EFSA J. 15 (12) (2017) 5077 ([228 pp.]. 15(12) 228, 2017).

[5] N.F.D. Silva, J.M.C.S. Magalhães, C. Freire, C. Delerue-Matos, Electrochemical biosensors for Salmonella: state of the art and challenges in food safety assessment, Biosens. Bioelectron. 99 (2018) 667-682.

[6] P. Arora, A. Sindhu, N. Dilbaghi, A. Chaudhury, Biosensors as innovative tools for the detection of food borne pathogens, Biosens. Bioelectron. 28 (1) (2011) 1-12

[7] J.W.F. Law, N.S. Ab Mutalib, K.G. Chan, L.H. Lee, Rapid methods for the detection of foodborne bacterial pathogens: principles, applications, advantages and limitations, Front. Microbiol. 5 (2015) 19.

[8] R. Liang, J. Ding, S. Gao, W. Qin, Mussel-inspired surface-imprinted sensors for Potentiometric label-free detection of biological Species, Angew. Chem. Int. Ed. 56 (24) (2017) 6833-6837.

[9] T. Yin, W. Qin, Applications of nanomaterials in potentiometric sensors, TrAC Trends Anal. Chem. 51 (2013) 79-86.

[10] J. Shu, Z. Qiu, S. Lv, K. Zhang, D. Tang, Plasmonic enhancement coupling with defect-engineered TiO2-x: a mode for sensitive photoelectrochemical biosensing, Anal. Chem. 90 (4) (2018) 2425-2429.

[11] G.A. Zelada-Guillén, J. Riu, A. Düzgün, F.X. Rius, Immediate detection of living bacteria at ultralow concentrations using a carbon nanotube based potentiometric Aptasensor, Angew. Chem. Int. Ed. 48 (40) (2009) 7334-7337.

[12] G.A. Zelada-Guillén, S.V. Bhosale, J. Riu, F.X. Rius, Real-time potentiometric detection of bacteria in complex samples, Anal. Chem. 82 (22) (2010) 9254-9260.

[13] E. Bakker, Electroanalysis with membrane electrodes and liquid-liquid interfaces, Anal. Chem. 88 (1) (2016) 395-413.

[14] T. Vigassy, W.E. Morf, M. Badertscher, A. Ceresa, N.F. de Rooij, E. Pretsch, Making use of ion fluxes through potentiometric sensor membranes: ISEs with step responses at critical ion activities, Sens. Actuators B: Chem. 76 (1) (2001) 477-482.

[15] M. Pawlak, G. Mistlberger, E. Bakker, Concanavalin A electrochemical sensor based on the surface blocking principle at an ion-selective polymeric membrane, Microchim. Acta 182 (1) (2015) 129-137.

[16] Y. Xu, E. Bakker, Ion channel mimetic chronopotentiometric polymeric membrane ion sensor for surface confined protein detection, Langmuir: ACS J. Surf. Colloids 25 (1) (2009) 568-573.

[17] M.S. Ozdemir, M. Marczak, H. Bohets, K. Bonroy, D. Roymans, L. Stuyver, K. Vanhoutte, M. Pawlak, E. Bakker, A label-free potentiometric sensor principle for the detection of antibody-antigen interactions, Anal. Chem. 85 (9) (2013) 4770-4776.

[18] S. Lv, Z. Lin, K. Zhang, M. Lu, D. Tang, Polyion oligonucleotide-decorated gold nanoparticles with tunable surface charge density for amplified signal output of potentiometric immunosensor, Anal. Chim. Acta 964 (2017) 67-73.

[19] K. Zhang, S. Lv, Z. Lin, M. Li, D. Tang, Bio-bar-code-based photoelectrochemical immunoassay for sensitive detection of prostate-specific antigen using rolling circle amplification and enzymatic biocatalytic precipitation, Biosens. Bioelectron. 101 (2018) 159-166.

[20] M.H. Jazayeri, H. Amani, A.A. Pourfatollah, H. Pazoki-Toroudi, 
B. Sedighimoghaddam, Various methods of gold nanoparticles (GNPs) conjugation to antibodies, Sens. Bio-Sens. Res. 9 (2016) 17-22.

[21] M.I.G.S. Almeida, R.W. Cattrall, S.D. Kolev, Polymer inclusion membranes (PIMs) in chemical analysis - a review, Anal. Chim. Acta 987 (Suppl. C) (2017) 1-14.

[22] L.D. Nghiem, P. Mornane, I.D. Potter, J.M. Perera, R.W. Cattrall, S.D. Kolev, Extraction and transport of metal ions and small organic compounds using polymer inclusion membranes (PIMs), J. Membr. Sci. 281 (1-2) (2006) 7-41.

[23] D. Wang, Y. Liu, X. Zhou, J. Sun, T. You, EDTA-controlled one-pot preparation of novel shaped gold microcrystals and Their application in surface-enhanced Raman Scattering, Chem. Lett. 36 (7) (2007) 924-925.

[24] D. He, D.S. He, J. Yang, Z.-X. Low, R. Malpass-Evans, M. Carta, N.B. McKeown, F. Marken, Molecularly rigid microporous polyamine captures and stabilizes conducting platinum nanoparticle networks, ACS Appl. Mater. Interfaces 8 (34) (2016) 22425-22430.

[25] J.G. Kim, M.C. Cha, J. Lee, T. Choi, J.Y. Chang, Preparation of a sulfur-functionalized microporous polymer sponge and in situ growth of silver Nanoparticles: a compressible monolithic catalyst, ACS Appl. Mater. Interfaces 9 (43) (2017) 38081-38088.

[26] H.-L. Cao, H.-B. Huang, Z. Chen, B. Karadeniz, J. Lü, R. Cao, Ultrafine silver nanoparticles supported on a conjugated microporous polymer as high-performance nanocatalysts for nitrophenol reduction, ACS Appl. Mater. Interfaces 9 (6) (2017) 5231-5236.

[27] M. Freitas, S. Viswanathan, H.P.A. Nouws, M.B.P.P. Oliveira, C. Delerue-Matos, Iron oxide/gold core/shell nanomagnetic probes and CdS biolabels for amplified electrochemical immunosensing of Salmonella typhimurium, Biosens. Bioelectron. 51 (2014) 195-200.

[28] S. Viswanathan, C. Rani, J.-aA. Ho, Electrochemical immunosensor for multiplexed detection of food-borne pathogens using nanocrystal bioconjugates and MWCNT screen-printed electrode, Talanta 94 (2012) 315-319.

[29] Y.Y.N. Bonggotgetsakul, R.W. Cattrall, S.D. Kolev, The preparation of a gold nanoparticle monolayer on the surface of a polymer inclusion membrane using EDTA as the reducing agent, J. Membr. Sci. 379 (1-2) (2011) 322-329.

[30] R. Barlag, F. Nyasulu, R. Starr, J. Silverman, P. Arthasery, L. McMills, A studentmade silver-silver chloride reference electrode for the general chemistry laboratory: $\sim 10$ min preparation, J. Chem. Educ. 91 (5) (2014) 766-768.

[31] R. Guo, L. Zhang, Z. Zhu, X. Jiang, Direct facile approach to the fabrication of Chitosan - Gold hybrid nanospheres, Langmuir 24 (7) (2008) 3459-3464.

[32] J.-O. Lee, H.-M. So, E.-K. Jeon, H. Chang, K. Won, Y.H. Kim, Aptamers as molecular recognition elements for electrical nanobiosensors, Anal. Bioanal. Chem. 390 (4) (2008) 1023-1032.

[33] V. Silin, H. Weetall, D.J. Vanderah, SPR studies of the nonspecific Adsorption kinetics of human IgG and BSA on gold surfaces modified by Self-Assembled Monolayers (SAMs), J. Colloid Interface Sci. 185 (1) (1997) 94-103.

[34] E.A. Khudaish, M. Al-Hinaai, S. Al-Harthy, K. Laxman, Electrochemical oxidation of chlorpheniramine at polytyramine film doped with ruthenium (II) complex: measurement, kinetic and thermodynamic studies, Electrochim. Acta 135 (2014) 319-326.

[35] M. Pawlak, E. Grygolowicz-Pawlak, G.A. Crespo, G. Mistlberger, E. Bakker, PVCbased ion-selective electrodes with enhanced biocompatibility by surface modification with "Click" chemistry, Electroanalysis 25 (8) (2013) 1840-1846.

[36] Q. Cheng, Z. Chen, The cause analysis of the incomplete semi-circle observed in high frequency region of EIS obtained from TEL-covered pure copper, Int. J. Electrochem. Sci. 8 (2013) 8282-8290.

[37] N. Mahato, M.M. Singh, Investigation of passive film properties and pitting resistance of AISI 316 in aqueous Ethanoic acid containing chloride ions using electrochemical impedance spectroscopy(EIS), Portugaliae, Electrochim. Acta 29
(2011) 233-251.

[38] M. Saafi, G. Piukovics, J. Ye, Hybrid graphene/geopolymeric cement as a superionic conductor for structural health monitoring applications, Smart Mater. Struct. 25 (10) (2016) 105018.

[39] H. Dozol, G. Mériguet, B. Ancian, V. Cabuil, H. Xu, D. Wang, A. Abou-Hassan, On the synthesis of Au nanoparticles using EDTA as a reducing agent, J. Phys. Chem. C 117 (40) (2013) 20958-20966.

[40] M. Aghazadeh, I. Karimzadeh, M.R. Ganjali, Ethylenediaminetetraacetic acid capped superparamagnetic iron oxide ( $\mathrm{Fe} 3 \mathrm{O} 4)$ nanoparticles: a novel preparation method and characterization, J. Magn. Magn. Mater. 439 (2017) 312-319.

[41] Y. Aceta, M. del Valle, Graphene electrode platform for impedimetric aptasensing, Electrochim. Acta 229 (Suppl. C) (2017) 458-466.

[42] A.H. Loo, A. Bonanni, M. Pumera, Biorecognition on graphene: physical, covalent, and affinity immobilization methods exhibiting dramatic differences, Chem. - Asian J. 8 (1) (2013) 198-203.

[43] A.H. Loo, A. Bonanni, M. Pumera, Thrombin aptasensing with inherently electroactive graphene oxide nanoplatelets as labels, Nanoscale 5 (11) (2013) 4758-4762.

[44] Y. Sun, L.J. Kirschenbaum, I. Kouadio, Kinetics and mechanism of the multi-step oxidation of ethylenediaminetetraacetate by $[\mathrm{Ag}(\mathrm{OH}) 4]$ - in alkaline media, J. Chem. Soc. Dalton Trans. 9 (1991) 2311-2315.

[45] Chapter 15 Processing of data and reporting of results of enzyme immunoassays, in: P. Tijssen (Ed.), Laboratory Techniques in Biochemistry and Molecular Biology, Elsevier, 1985, pp. 385-421.

[46] N. Ostrov, M. Jimenez, S. Billerbeck, J. Brisbois, J. Matragrano, A. Ager, V.W. Cornish, A modular yeast biosensor for low-cost point-of-care pathogen detection, Sci. Adv. 3 (6) (2017).

[47] N.F.D. Silva, J.M.C.S. Magalhaes, M.T. Oliva-Teles, C. Delerue-Matos, A potentiometric magnetic immunoassay for rapid detection of Salmonella typhimurium, Anal. Methods 7 (9) (2015) 4008-4011.

[48] N. Punbusayakul, S. Talapatra, P.M. Ajayan, W. Surareungchai, Label-free as-grown double wall carbon nanotubes bundles for Salmonella typhimurium immunoassay, Chem. Cent. J. 7 (2013) 8.

[49] S. Ranjbar, S. Shahrokhian, F. Nurmohammadi, Nanoporous gold as a suitable substrate for preparation of a new sensitive electrochemical aptasensor for detection of Salmonella typhimurium, Sens. Actuators B: Chem. 255 (2018) 1536-1544.

[50] P.-D. Nguyen, T.B. Tran, D.T.X. Nguyen, J. Min, Magnetic silica nanotube-assisted impedimetric immunosensor for the separation and label-free detection of Salmonella typhimurium, Sens. Actuators B: Chem. 197 (2014) 314-320.

[51] V. Nandakumar, J.T. La Belle, J. Reed, M. Shah, D. Cochran, L. Joshi, T.L. Alford, A methodology for rapid detection of Salmonella typhimurium using label-free electrochemical impedance spectroscopy, Biosens. Bioelectron. 24 (4) (2008) 1039-1042.

[52] J. Dong, H. Zhao, M. Xu, Q. Ma, S. Ai, A label-free electrochemical impedance immunosensor based on AuNPs/PAMAM-MWCNT-Chi nanocomposite modified glassy carbon electrode for detection of Salmonella typhimurium in milk, Food Chem. 141 (3) (2013) 1980-1986.

[53] Z. Farka, T. Juř́k, M. Pastucha, D. Kovář, K. Lacina, P. Skládal, Rapid immunosensing of Salmonella Typhimurium using electrochemical impedance spectroscopy: the effect of sample treatment, Electroanalysis 28 (8) (2016) 1803-1809.

[54] L. Zhou, R. Yuan, Y. Chai, On-Off PVC membrane based Potentiometric immunosensor for label-free detection of alpha-fetoprotein, Electroanalysis 19 (11) (2007) 1131-1138.

[55] I.-S. Park, W.-Y. Kim, N. Kim, Operational characteristics of an antibody-immobilized QCM system detecting Salmonella spp, Biosens. Bioelectron. 15 (3) (2000) 167-172. 